\title{
Influence of gap junction intercellular communication composed of connexin 43 on the antineoplastic effect of adriamycin in breast cancer cells
}

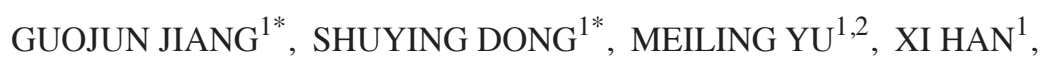 \\ $\mathrm{CHAO}_{\mathrm{ZHENG}}{ }^{1}$, XIAOGUANG ZHU ${ }^{1}$ and XUHUI TONG ${ }^{1}$ \\ ${ }^{1}$ Faculty of Pharmacy, Bengbu Medical College, Bengbu, Anhui 233030; ${ }^{2}$ Department of Pharmacy, \\ The First Affiliated Hospital of Bengbu Medical College, Bengbu, Anhui 233004, P.R. China
}

Received May 25, 2015; Accepted October 6, 2016

DOI: $10.3892 / \mathrm{ol} .2016 .5471$

\begin{abstract}
Gap junctions (GJs) serve the principal role in the antineoplastic (cytotoxicity and induced apoptosis) effect of chemical drugs. The aim of the present study was to determine the effect of GJ intercellular communication (GJIC) composed of connexin 43 (Cx43) on adriamycin cytotoxicity in breast cancer cells. Four cell lines (Hs578T, MCF-7, MDA-MB-231 and SK-BR-3) with different degree of malignancy were used in the study. The results of western blotting and immunofluorescence revealed that, in Hs578T and MCF-7 cells, which have a low degree of malignancy, the expression levels of $\mathrm{Cx} 43$ and GJIC were higher than those in MDA-MB-231 and SK-BR-3 cells (which have a high degree of malignancy). In Hs578T and MCF-7 cells, where GJ could be formed, the function of GJ was modulated by a pharmacological potentiators [retinoid acid (RA)]/inhibitors [oleamide and 18- $\alpha$-glycyrrhetinic acid (18- $\alpha-\mathrm{GA})]$ and small interfering RNA (siRNA). In high-density cells (where GJ was formed), enhancement of GJ function by RA increased the cytotoxicity of adriamycin, while inhibition of GJ function by oleamide/18- $\alpha-\mathrm{GA}$ and siRNA decreased the cytotoxicity caused by adriamycin. Notably, the modulation of GJ did not affect the survival of cells treated with adriamycin when cells were in low density (no GJ was formed). The present study illustrated the association between GJIC and the antitumor effect of adriamycin in breast cancer cells. The cytotoxicity of adriamycin on breast cancer cells was increased when the function of gap junctions was enhanced.
\end{abstract}

Correspondence to: Mr. Xuhui Tong, Faculty of Pharmacy, Bengbu Medical College, 2600 Donghai Road, Bengbu, Anhui 233030, P.R. China

E-mail: bbmctxh@126.com

"Contributed equally

Key words: adriamycin, gap junction, connexin 43, breast cancer

\section{Introduction}

Breast cancer is one of the most common malignancies in women worldwide and accounts for $>15 \%$ of all female cancer mortalities as a result of tumor proliferation and metastasis (1). Excessive proliferation of tumors is the most serious characteristic of neoplastic cells, which have a crucial role in the imbalance of tissue homeostasis $(2,3)$.

Adriamycin is the most effective chemotherapeutic agent in the treatment of breast cancer $(4,5)$. However, adriamycin efficacy is often limited by the emergence of resistance and adverse reactions $(6,7)$. Therefore, improvements in the clinical application of adriamycin and the reduction of its adverse reactions are crucial.

Gap junctions (GJs) formed by connexins are the only communication junctions identified in animal tissues, and are responsible for the direct trafficking of ions, molecules and several second messengers, including inositol 1,4,5-trisphosphate, $\mathrm{Ca}^{2+}$, glutathione and cyclic adenosine monophosphate (8). Connexins that form GJ channels are involved in the exchange of molecular signals in the cytoplasm of neighboring cells $(9,10)$. Decreased expression of connexins and/or absence of GJ intercellular communication (GJIC) have been associated with tumor phenotype $(11,12)$. Intercellular junctions are important in the maintenance of cellular homeostasis, cell differentiation and cellular death (13). In normal mammary tissues, connexin 43 (Cx43) was shown to be mostly present in the myoepithelial cells and to be required for myoepithelial differentiation (14). Lack of Cx43 was a common feature of human mammary cancer tissues compared with non-neoplastic breast tissues surrounding primary tumors (15). Additionally, connexins have been reported to have functions independent of GJIC (16,17). Qin et al (18) reported that the tumor growth of human breast cancer cells (MDA-MB-231) transfected with the Cx43 gene was suppressed independently of GJIC.

In the present study, the expression of Cx43 was determined in breast cancer cells with different malignancy degree. GJ potentiators/inhibitors and Cx43 mall interfering RNA (siRNA) were used to regulate the function of GJs in order to certify whether the modulation of adriamycin cytotoxicity 
was dependent or independent on GJs. In summary, the current study will illustrate the association between GJIC and the antineoplastic effect of adriamycin in breast cancer cells.

\section{Materials and methods}

Materials. Adriamycin, retinoic acid (RA), oleamide and 18 - $\alpha$-glycyrrhetinic acid (18- $\alpha$-GA) were purchased from Sigma-Aldrich (Merck Millipore, Darmstadt, Germany). Anti-Cx43 (cat. no. C8093) and anti- $\beta$-actin (cat. no. A5441) primary antibodies, and alkaline phosphatase-conjugated goat anti-mouse secondary antibodies, were acquired from Sigma-Aldrich (Merck Millipore). IgG-fluorescein isothiocyanate (FITC) for immunofluorescence (cat. no. LK-GAR4882) was purchased from Sigma-Aldrich (Merck Millipore). Calcein-acetoxymethyl ester (Calcein-AM) and Lipofectamine ${ }^{\mathrm{TM}} 2000$ were acquired from Invitrogen (Thermo Fisher Scientific, Inc.). All other reagents were obtained from Sigma-Aldrich (Merck Millipore) unless stated otherwise.

Cell lines and cell culture. Human breast cancer cell lines (Hs578T, MDA-MB-231 and SK-BR-3) (American Type Culture Collection, Manassas, VA, USA) were grown in Dulbecco's modified Eagle's medium (Invitrogen; Thermo Fisher Scientific, Inc.) supplemented with $10 \%$ (v/v) fetal bovine serum (FBS; Gibco; Thermo Fisher Scientific, Inc.) and $100 \mathrm{U} / \mathrm{ml}$ penicillin/streptomycin. MCF-7 cells were maintained in RPMI 1640 medium (Invitrogen; Thermo Fisher Scientific, Inc.) containing 10\% (v/v) FBS. All cell lines were grown at $37^{\circ} \mathrm{C}$ in a humidified atmosphere containing $95 \%$ air and $5 \%$ carbon dioxide.

Chemicals. All chemicals were prepared as stock solutions and stored at $-20^{\circ} \mathrm{C}$ in aliquots. Working solutions were freshly diluted at the time of the experiment. Stock solutions of adriamycin were prepared at $1 \mathrm{mmol} / \mathrm{l}$ in PBS. All exposures to adriamycin were performed in the dark. $18-\alpha-$ GA was dissolved in dimethyl sulfoxide (DMSO) at $10 \mathrm{mM}$ and diluted to a final concentration of $10 \mu \mathrm{M}$ in culture medium, while oleamide was dissolved in DMSO at $25 \mathrm{mM}$ and diluted to a final concentration of $25 \mu \mathrm{M}$ in culture medium, and then they were added to the cells prior to adriamycin treatment.

Modulation of GJIC. For potentiation, cells were incubated with the GJ potentiator RA (10 $\mu \mathrm{M}$ in DMSO) $24 \mathrm{~h}$ prior to adriamycin exposure and during the adriamycin treatment. For inhibition, cells were incubated with two GJ inhibitors, $18-\alpha-$ GA (10 $\mu \mathrm{M}$ in DMSO) and oleamide ( $25 \mu \mathrm{M}$ in DMSO) prior to adriamycin exposure and during the adriamycin treatment. Control cells were incubated with DMSO alone.

Western blotting. Western blot assays were conducted as reported in previous studies (19). Cells were washed three times with cold PBS. Then, cell lysates were prepared with cell wash buffer (Beyotime Institute of Biotechnology, Haimen, China) followed by 1-h incubation in lysis buffer [Tris $\cdot \mathrm{HCl}$ (pH 7.4) $20 \mathrm{mM}, \mathrm{NaCl} 150 \mathrm{mM}$, EDTA $1 \mathrm{mM}$, Triton $1 \%$, sodium pyrophosphate $2.5 \mathrm{mM}, \mathrm{Na}_{3} \mathrm{VO}_{4} 1 \mathrm{mM}$, $\beta$-glycerophosphate $1 \mathrm{mM}$ and protease inhibitors 1:1,000] on ice. Protein concentration was determined using the BCA Protein Assay kit (Bio-Rad Laboratories, Inc., Hercules, CA, USA). A total of $20 \mu \mathrm{g}$ of protein from each sample was separated by $10 \%$ SDS-PAGE and transferred to polyvinylidene difluoride membranes. Membranes were blocked with $5 \%$ (w/v) skimmed dry milk in wash buffer [0.01 mol/l PBS ( $\mathrm{pH} 7.4)$ and $0.05 \%$ (v/v) Tween 20]. Next, the membranes were incubated with monoclonal antibodies against $\mathrm{Cx} 43(1: 4,000)$ or $\beta$-actin $(1: 2,000)$ at $4^{\circ} \mathrm{C}$ overnight, followed by incubation with the alkaline phosphatase-conjugated goat anti-mouse secondary antibody $(1: 4,000)$ for $2 \mathrm{~h}$ at room temperature. The immunopositive bands were visualized using the Immobilon Western $^{\text {TM }}$ Chemiluminescent HRP Substrate (Merck Millipore) and quantified using Quantity One 4.62 software (Bio-Rad Laboratories, Inc.).

Immunofluorescence. Cells were grown to confluence on 6-well plates. Cells were fixed with $3.7 \%$ neutral buffered formalin in PBS containing Tween 20 (PBST) and permeabilized with ice-cold methanol for $30 \mathrm{~min}$ at $-20^{\circ} \mathrm{C}$. Cover slips were blocked with 5\% bovine serum albumin (BSA) (Sigma-Aldrich; Merck Millipore) in PBST for $2 \mathrm{~h}$, and then incubated with the primary antibody overnight at $4^{\circ} \mathrm{C}$. Anti-Cx43 antibody diluted 1:100 in 2\% BSA in PBST was used. Samples were washed three times with PBST the next day, followed by the addition of secondary anti-mouse IgG FITC-conjugated antibody at 1:200 dilution in 2\% BSA in PBST for $2 \mathrm{~h}$ at room temperature (in the dark). Cover slips were subsequently washed three times with PBST for $5 \mathrm{~min}$ and then stained with DAPI (100 ng/ml) (Sigma-Aldrich; Merck Millipore) in order to count the cells.

'Parachute' dye-coupling assay. The assay for GJ function was performed as described by Hong et al (20) and Tong et al (21). Donor cells and receiver cells were grown to confluence in 12-well plates. Donor cells from one well were double-labeled with $5 \mu \mathrm{M}$ calcein-AM, which is converted intracellularly into the GJ-permeable dye calcein. Calcein-AM was freshly made as a solution of $10 \mu \mathrm{g} / \mathrm{ml}$. Donor cells were then trypsinized and seeded onto the receiver cells at a 1:150 donor:receiver ratio. Donor cells were allowed to attach to the monolayer of receiver cells and form GJs for $4-5 \mathrm{~h}$ at $37^{\circ} \mathrm{C}$, and then examined with a fluorescence microscope (CK40; Olympus Corporation, Tokyo, Japan) and photographed. For each experimental condition, the average number of receiver cells containing dye per donor cell was visually determined and normalized to that of control cultures.

MTT assay. Cells were plated in a 96-well plate at a density of $1 \times 10^{4} \mathrm{cells} / \mathrm{ml}$ and, after $24 \mathrm{~h}$, the cells were pretreated with RA for $24 \mathrm{~h}$, oleamide for $1 \mathrm{~h}$ or $18-\alpha-G A$ for $1 \mathrm{~h}$ prior to treatment with $6 \mu \mathrm{M}$ adriamycin for $24 \mathrm{~h}$. Cell viability was assessed by MTT (Sigma-Aldrich; Merck Millipore) reduction assay at the appropriate time points, and the absorbance was read at $490 \mathrm{~nm}$ using a microplate reader (Bio-Rad Laboratories, Inc.).

RNA interference. Chemically synthesized siRNAs, which were acquired from Shanghai GenePharma Co., Ltd. (Shanghai, China) were transfected using TransMessenger Transfection 

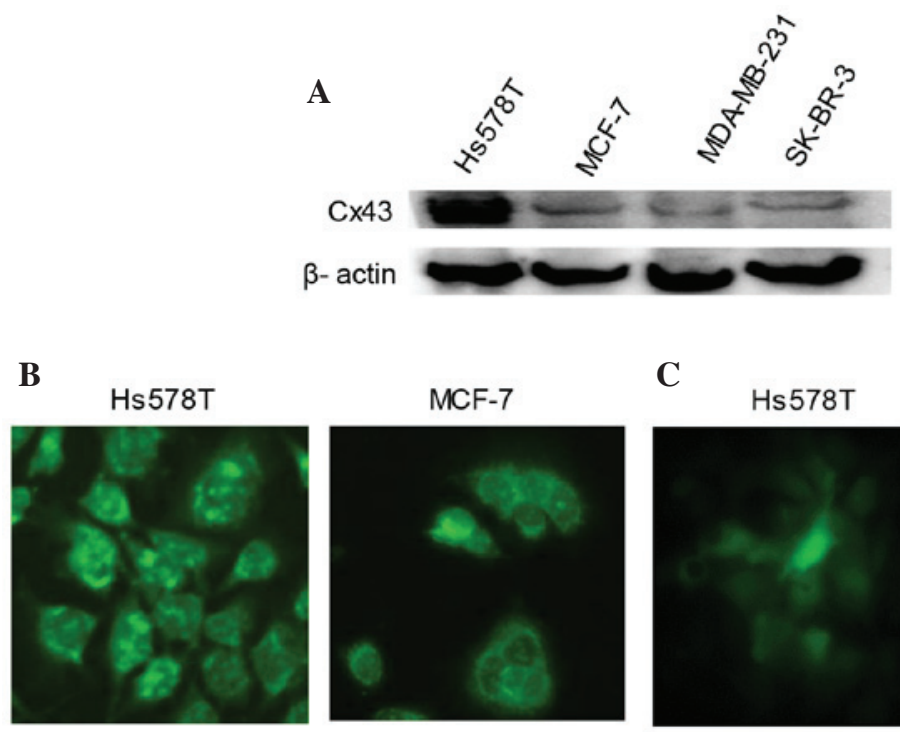

C
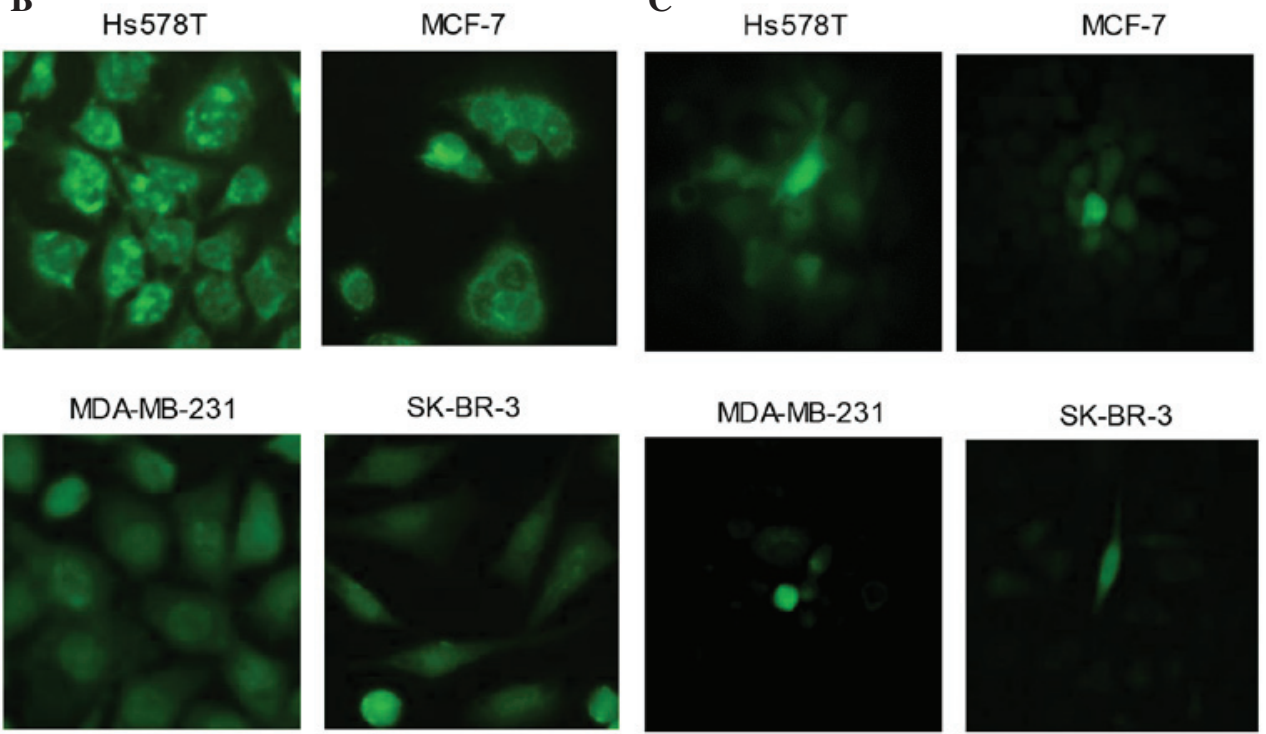

Figure 1. Expression of Cx43 in breast cancer cells (Hs578T, MCF-7, MDA-MB-231 and SK-BR-3). (A) Western blot analyses of total Cx43 protein in Hs578T, MCF-7, MDA-MB-231 and SK-BR-3 cells. (B) Fluorescence images show the expression of Cx43 on the membrane of breast cancer cells by immunofluorescence assay. (C) Fluorescence images show the degree of dye coupling by the 'parachute' dye-coupling assay. Magnifications, $\mathrm{x} 400$. Cx43, connexin 43 .

Reagent (Qiagen GmbH, Hilden, Germany) according to the manufacturer's specifications. Briefly, cells were subcultured into 6-well plates containing glass cover slip inserts and incubated under their normal growth conditions. On the day of transfection, cells were washed with Opti-MEM (Invitrogen; Thermo Fisher Scientific, Inc.) twice. Then, Opti-MEM and siRNA complex mixed with TranMessenger Transfection Reagent was applied to the cells and incubated for $6 \mathrm{~h}$ without antibiotics. For transiently transfected cells, a synthetic siRNA targeting Cx43 (target sequence, 5'-GGA AGC ACC AUC UCU AAC UTT-3') or negative control siRNA (target sequence, 5'-UUC UCC GAA CGU GUC ACG UTT-3') were transfected into cells by Lipofectamine ${ }^{\mathrm{TM}} 2000$. Cells were changed to a regular cell culture medium $48 \mathrm{~h}$ later. Cells were either fixed for immunocytochemical studies, or the cell lysates were collected and prepared for western blot analysis.

Statistical analysis. Data were expressed as the mean \pm standard deviation. Statistical significance was determined with one-way analysis of variance using SPSS version 17.0 (SPSS, Inc., Chicago, IL, USA). $\mathrm{P}<0.05$ was considered to indicate a statistically significant difference.

\section{Results}

Expression of Cx43 in breast cancer cells. 'Parachute' dye-coupling assay was used to detect the function of GJ in human breast cancer cells. Fig. 1 indicates that Hs578T and
MCF-7 formed complete GJs. However, there was no effective GJ formed in MDA-MB-231 or SK-BR-3 cells.

In four types of human mammary cancer cells, western blotting and immunofluorescence were used to detect total $\mathrm{Cx} 43$ protein (Fig. 1A) and $\mathrm{Cx} 43$ protein on the membrane of cells (Fig. 1B), respectively. Fig. 1A and B demonstrate that Hs578T cells expressed the highest level of $\mathrm{Cx} 43$, followed by MCF-7 and SK-BR-3 cells, while MDA-MB-231 cells expressed the lowest level of $\mathrm{Cx} 43$.

Since MDA-MB-231 and SK-BR-3 cells could not form effective GJs (Fig. 1C), the subsequent experiments were conducted on Hs578T and MCF-7 cells, which expressed higher $\mathrm{Cx} 43$ protein levels, to detect the influence of GJ potentiators/inhibitors on the cytotoxicity of adriamycin.

Influence of GJ potentiator on the cytotoxicity of adriamycin. To determine whether GJIC was required for the increase of adriamycin-induced cytotoxicity in cells with GJIC, the breast cancer cells Hs578T and MCF-7 were treated with chemical modulators of GJs prior and during exposure to $6 \mu \mathrm{M}$ adriamycin [inhibitor, oleamide $(22,23)$ or 18 - $\alpha$-GA $(24,25)$; potentiator, RA $(21,26)]$ at high density (GJ formed) or low density (no GJ formed).

Fig. 2A and B revealed that treatment of Hs578T or MCF-7 cells with $10 \mu \mathrm{M}$ RA for $24 \mathrm{~h}$ increased intercellular dye coupling through GJs. Fig. $2 \mathrm{C}$ illustrated that pretreatment of cells with RA for $24 \mathrm{~h}$ increased the cytotoxicity of adriamycin, leading to a substantially decreased surviving 
A
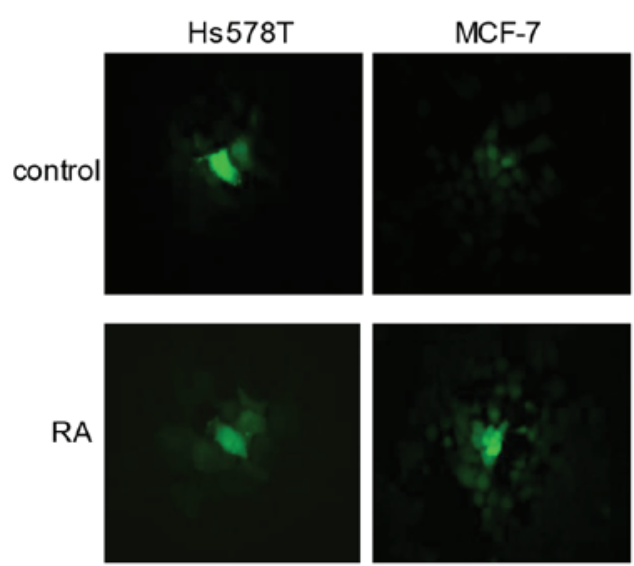

C

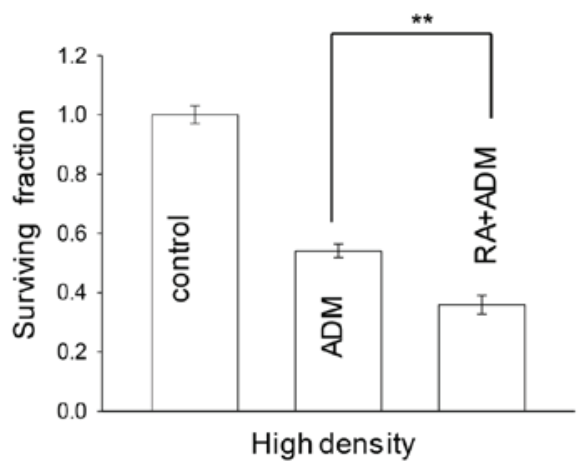

MCF-7

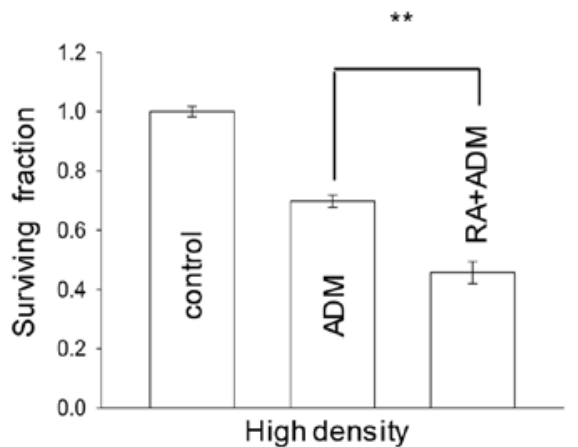

Hs578T

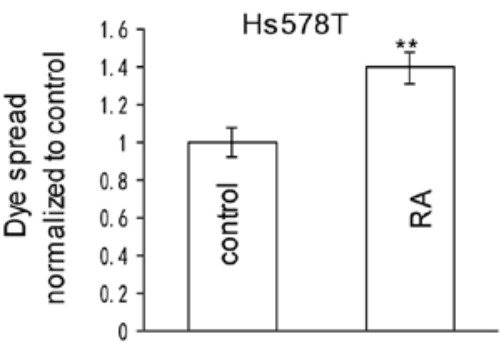

MCF-7

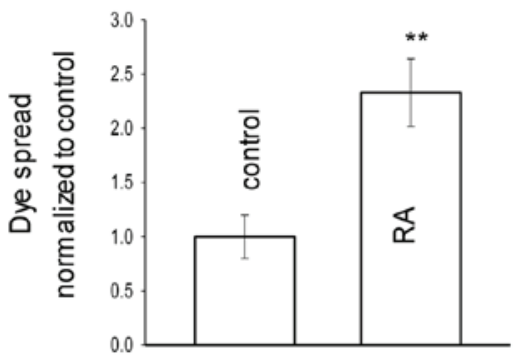

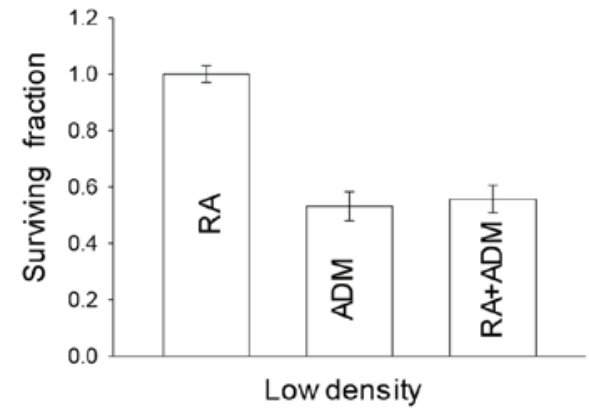

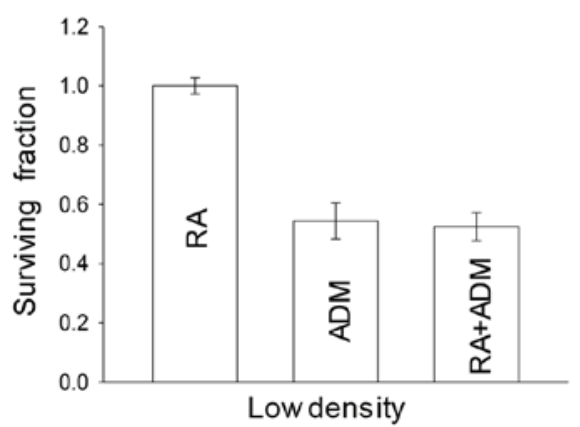

Figure 2. Effect of RA on the cytotoxicity of ADM. (A) Fluorescence images show the degree of dye coupling by the 'parachute' dye-coupling assay (magnification, $\mathrm{x} 400)$. RA $(10 \mu \mathrm{M})$ increased gap junction intercellular communication in the two cell types analyzed. (B) Histograms show the quantitation of dye coupling. N=4; Bars are means \pm SD. ${ }^{* *} \mathrm{P}<0.01$ vs. the control group. (C) Surviving fraction of Hs578T and MCF-7 cells expressing Cx43 incubated with $6 \mu \mathrm{M}$ ADM for $24 \mathrm{~h}$, with or without $10 \mu \mathrm{M} \mathrm{RA}$, at high- and low-cell density. $\mathrm{N}=4$; Bars are means $\pm \mathrm{SD}$. ${ }^{* *} \mathrm{P}<0.01$, vs. the ADM group. Cx43, connexin 43 ; RA, retinoic acid; ADM, adriamycin; SD, standard deviation.

fraction in high-density cultures. However, at low-cell density, there was very little effect of RA on adriamycin toxicity. The results suggested that the enhancement of GJ function by RA increases the effect of adriamycin cytotoxicity (Fig. 2C).

Overall, the data indicated that the density dependence of adriamycin responses was a function of GJIC, and that RA increased the cytotoxicity of adriamycin in breast cancer cell lines.

Influence of GJ inhibitors on the cytotoxicity of adriamycin. The 'parachute' dye-coupling assay was used to determine the effect of oleamide or 18- $\alpha$-GA on the GJIC of mammary cancer 
A

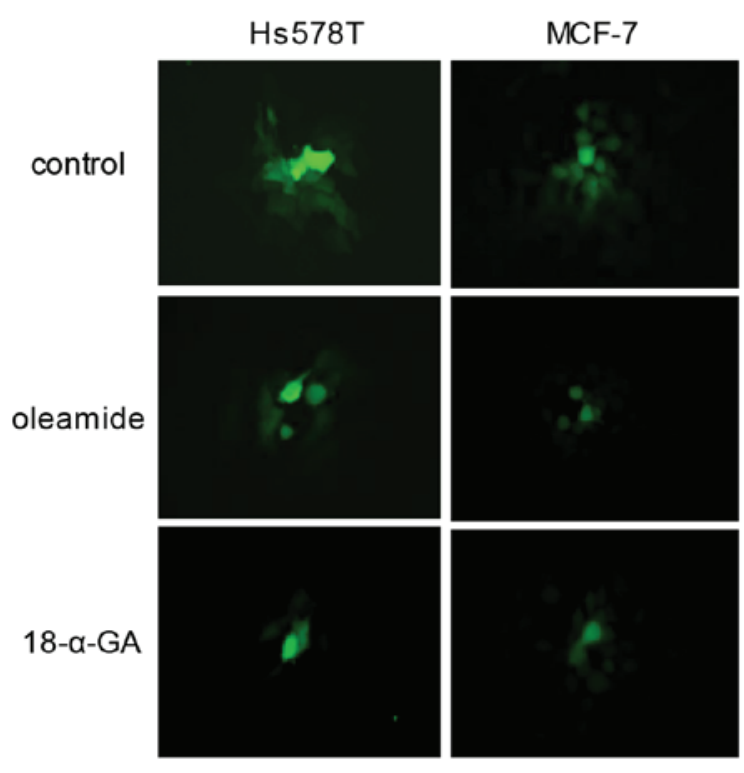

C

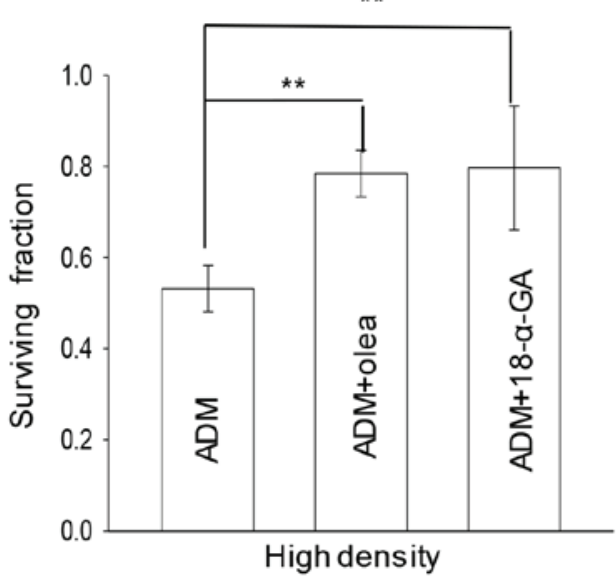

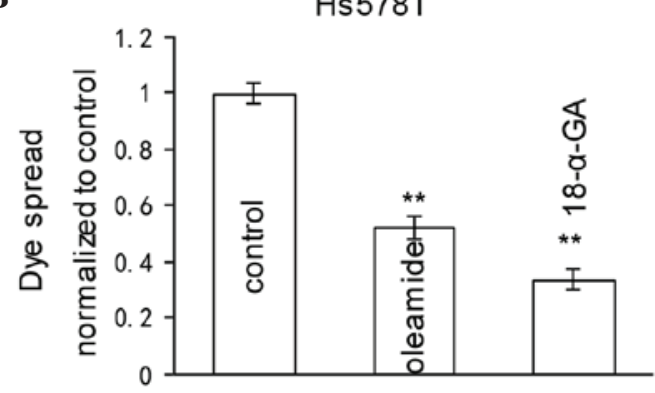

MCF-7

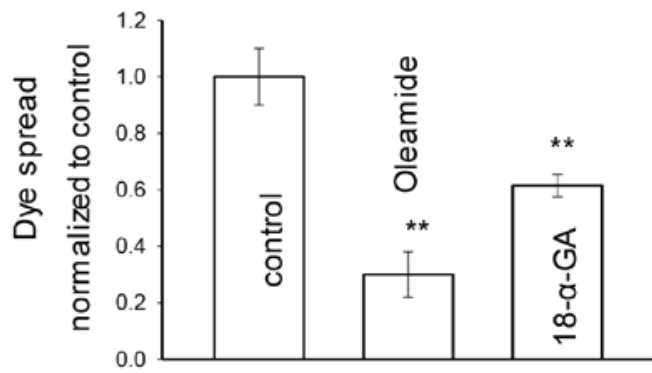

Hs578T

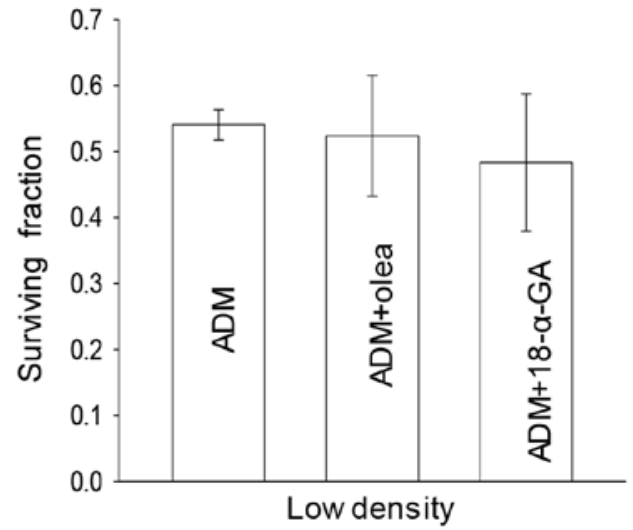

MCF-7
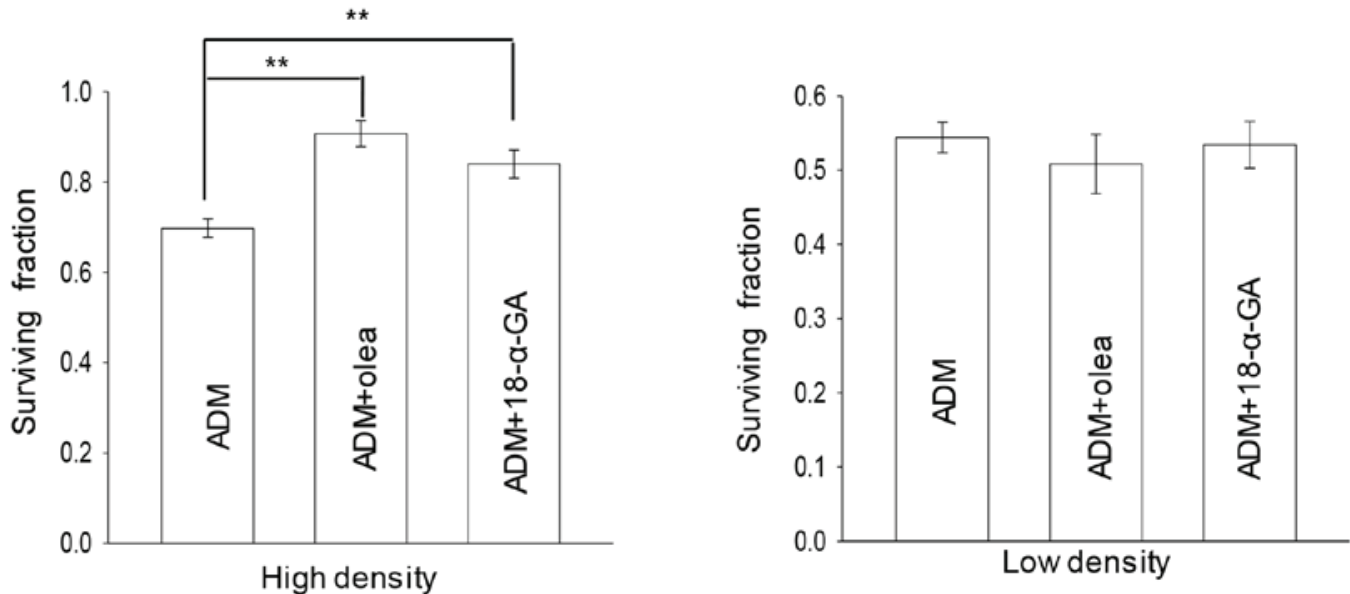

Figure 3. Effect of oleamide or 18- $\alpha$-GA on the cytotoxicity of ADM. (A) Fluorescence images show the degree of dye coupling by the 'parachute' dye-coupling assay (magnification, $\mathrm{x} 400)$. Oleamide $(25 \mu \mathrm{M})$ or $10 \mu \mathrm{M} 18-\alpha-$ GA decreased gap junction intercellular communication in the two cell types evaluated. (B) Histograms show the quantitation of dye coupling. N=4; Bars are means \pm SD. ${ }^{* *} \mathrm{P}<0.01$ vs. the control group. (C) Surviving fraction of Hs578T and MCF-7 cells expressing connexin 43 upon incubation with $6 \mu \mathrm{M}$ ADM for $24 \mathrm{~h}$, with or without either $25 \mu \mathrm{M}$ oleamide or $10 \mu \mathrm{M} 18-\alpha-\mathrm{GA}$, at high- and low-cell density. $\mathrm{N}=4$; Bars are means $\pm \mathrm{SD} .{ }^{* *} \mathrm{P}<0.01$ vs. the ADM group. ADM, adriamycin; SD, standard deviation; 18 - $\alpha$-GA, 18 - $\alpha$-glycyrrhetinic acid. 


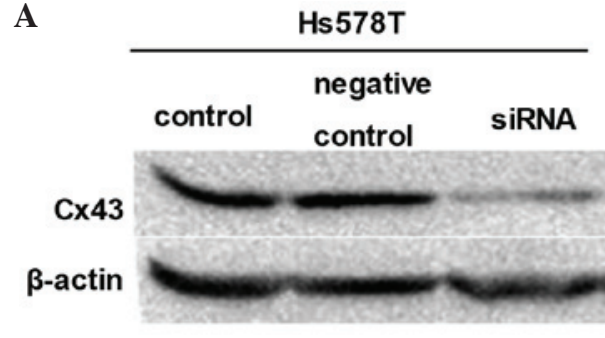

C

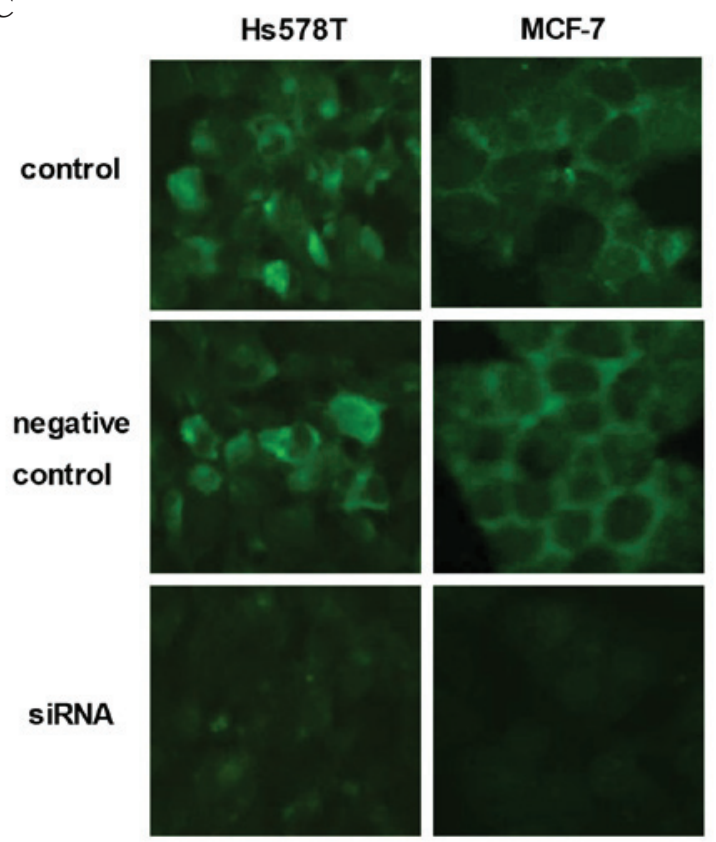

B

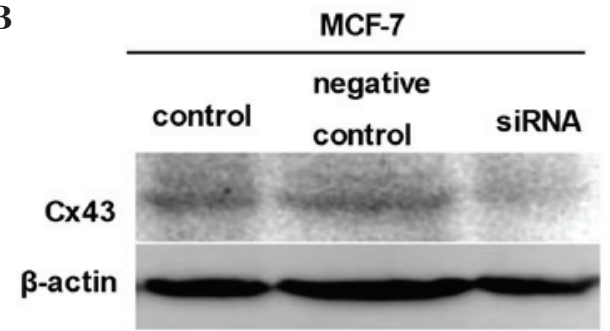

Figure 4. Effect of siRNA-mediated knockdown of Cx43 expression and gap junction intercellular communication. (A and B) Western blot analyses of siRNA-mediated knockdown of Cx43 expression in (A) Hs578T and (B) MCF-7 cells. (C) Fluorescence images show the expression of Cx43 on the membrane of Hs578T and MCF-7 cells by immunofluorescence assay (magnification, $\mathrm{x} 400$ ). Cells in which Cx43 expression was knocked down by siRNA exhibited lower levels of Cx43 than control cells (not treated with siRNA) and cells expressing Cx43 or cells transfected with negative control siRNA. Cx43, connexin 43; siRNA, small interfering RNA.

cells expressing Cx43. Fig. 3A and B indicated that treatment with $25 \mu \mathrm{M}$ oleamide or $10 \mu \mathrm{M} 18-\alpha-\mathrm{GA}$ for $1 \mathrm{~h}$ significantly inhibited GJIC in the cells, according to the results of the dye-transfer assay. As presented in Fig. 3C, pretreatment of cells with oleamide or $18-\alpha-$ GA for $1 \mathrm{~h}$ reduced the cytotoxicity of adriamycin, resulting in substantially increased survival in high-density cultures. However, at low density, there was very little effect of GJ inhibitor on adriamycin toxicity (Fig. 3C). The results suggest that inhibition of GJ function by oleamide or $18-\alpha-G A$ decreases adriamycin cytotoxicity in breast cancer cell lines.

Influence of siRNA on Cx43 expression and function of GJ. To further assess the role of GJIC in cell density-dependent adriamycin sensitivity, siRNA was used to downregulate the expression of $\mathrm{Cx} 43$ in these cells $(27,28)$. Downregulation was achieved by transient transfection of Hs578T and MCF-7 cells with synthetic Cx43-targeted siRNA. Cells were pretreated with siRNA negative control or Cx43 siRNA for $48 \mathrm{~h}$. Western blot analyses confirmed that, in the two breast cancer cell lines (Hs578T and MCF-7), the expression of Cx43 was markedly reduced relative to their untreated counterparts (control groups) and siRNA negative controls (Fig. 4A and B). In order to form an integrated GJ, connexins must be transferred to the membrane of cells $(29,30)$. Consistent with the results of western blotting, the expression of $\mathrm{Cx} 43$ on the membrane determined by immunofluorescence assay was also reduced (Fig. 4C).

Influence of siRNA on adriamycin cytotoxicity in breast cancer cells. To test whether siRNA would affect the function of GJs, a 'parachute' dye-coupling assay was used to detect dye coupling in breast cancer cells that were pretreated with siRNAs. In Hs578T and MCF-7 cells, the GJ-permeable dye calcein passed from the preloaded cells to various surrounding cells. According to the results of the 'parachute' dye-coupling assay (Fig. 5A and B), when breast cancer cells were incubated with siRNA for $48 \mathrm{~h}$, the dye coupling through the GJ was significantly decreased $(\mathrm{P}<0.01)$. However, negative control cells did not exhibit any significant change compared with the control group $(\mathrm{P}>0.05)$.

In order to determine whether siRNA could affect the adriamycin cytotoxicity in Hs578T cells, the cytotoxicity caused by $6 \mu \mathrm{M}$ adriamycin was analyzed in Hs578T and MCF-7 cells in high-density cultures (GJ formed) and low-density cultures (no GJ formed). Cells were pretreated with siRNA 
A

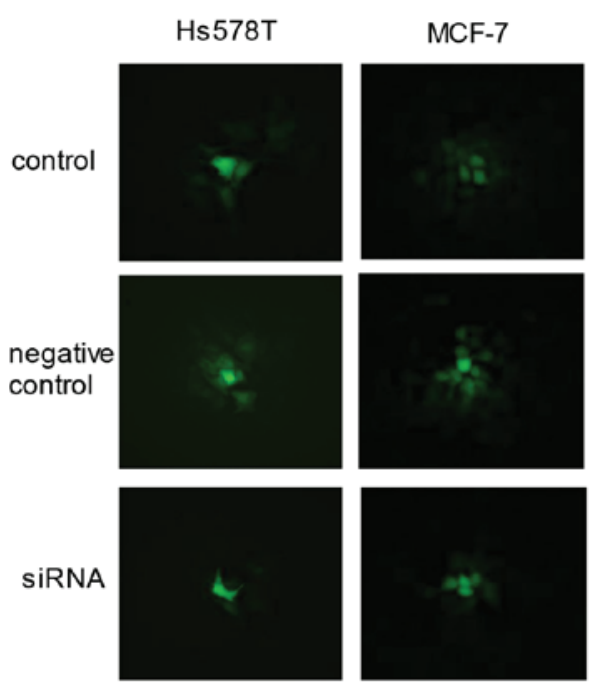

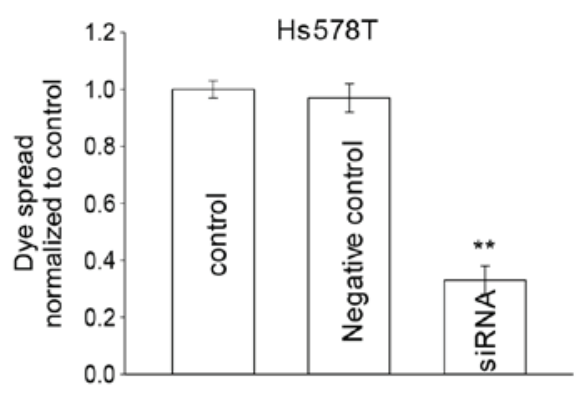

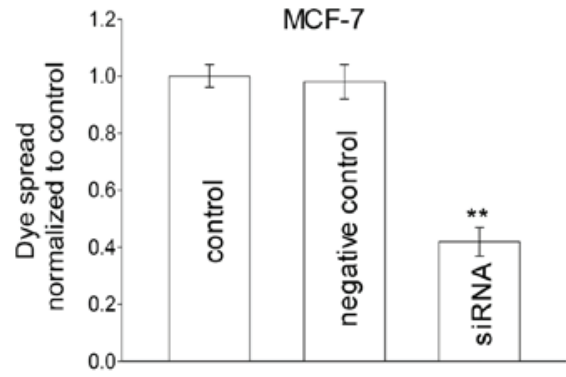

$\mathbf{C}$

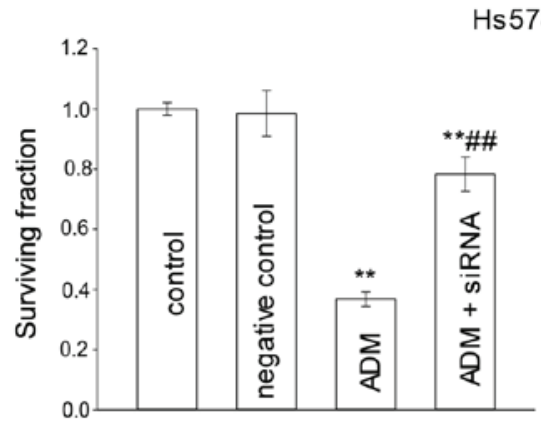

High density

Hs578T

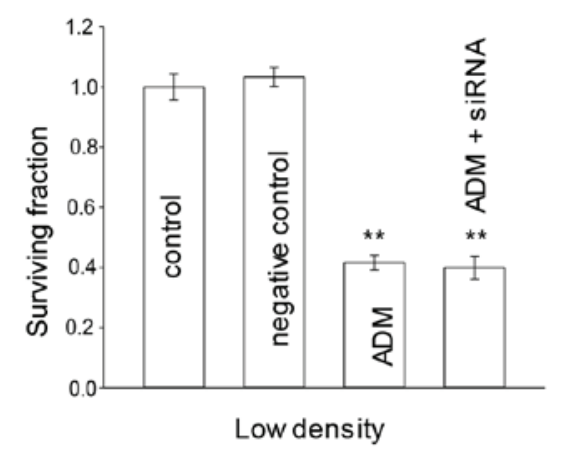

MCF-7
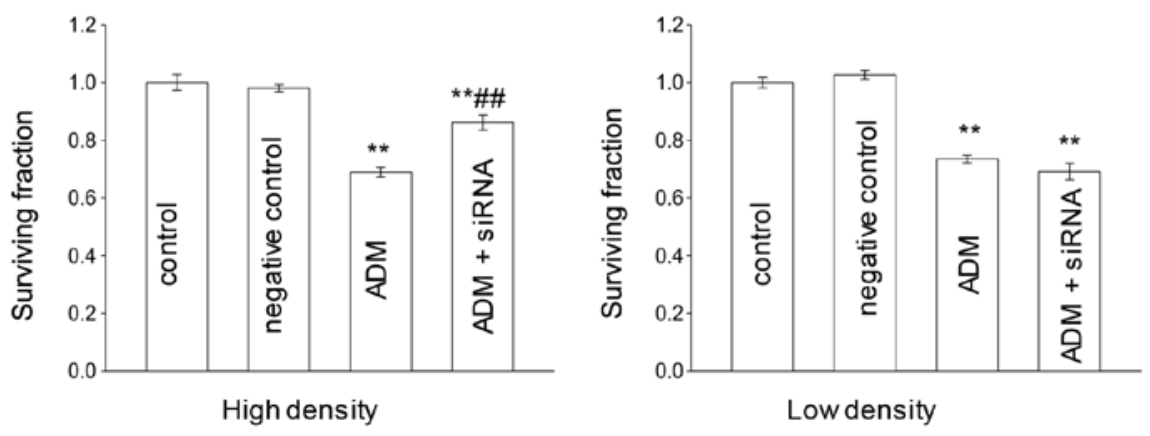

Figure 5. Effect of siRNA-mediated knockdown of Cx43 expression on ADM cytotoxicity. (A) Fluorescence images show the degree of dye coupling by the 'parachute' dye-coupling assay (magnification, $\mathrm{x} 400$ ). Cells in which Cx43 expression was knocked down by siRNA exhibited a lower extent of dye transfer than control cells (not treated with siRNA) and cells expressing Cx43 or cells transfected with negative control siRNA. (B) Histograms show the quantitation of dye coupling. $\mathrm{N}=4$; Bars are means $\pm \mathrm{SD} .{ }^{* *} \mathrm{P}<0.01$ vs. the control group. (C) Survival fraction of Hs578T and MCF-7 cells incubated with $6 \mu \mathrm{M}$ ADM and then transfected with negative control siRNA or $\mathrm{Cx} 43$ siRNA at high- or low-cell density. Bars are means $\pm \mathrm{SD}$. $\mathrm{N}=3 .{ }^{* *} \mathrm{P}<0.01$ vs. the control group. ${ }^{\# *} \mathrm{P}<0.01$ vs. the ADM group. ADM, adriamycin; SD, standard deviation; siRNA, small interfering RNA; Cx43, connexin 43.

for 48 h. Fig. 5C revealed that, in low-density cultures, the surviving fraction in the siRNA group was similar to that in the control group. This result demonstrated that siRNA had no effect on the adriamycin-induced cytotoxicity in Hs578T and MCF-7 cells when no GJs were formed. It suggests that, in the absence of GJIC, downregulation of $\mathrm{Cx} 43$ expression had no effect on the cellular response to adriamycin. Thus, Cx43 expression itself did not exert modulatory effects on adriamycin cytotoxicity that were unrelated to GJ formation and function. By contrast, in high-density cultures, when cells were exposed to $6 \mu \mathrm{M}$ adriamycin, the surviving fraction of the siRNA group was increased compared with that of the control group. This result demonstrated that knockdown of $\mathrm{Cx} 43$ expression by siRNA reduced the cytotoxicity of adriamycin in mammary tumor cells when GJs were formed (Fig. 5C). 


\section{Discussion}

The present study demonstrated that there was a significant GJ-dependent component of adriamycin toxicity in breast cancer cells. Our results indicated that the expression levels of $\mathrm{Cx} 43$ in breast cancer cells were associated with malignancy. In the present study, Hs578T cells, which had the lowest malignancy degree, expressed the highest level of $\mathrm{Cx} 43$, followed by MCF-7, SK-BR-3 and MDA-MB-231 cells, where cells with the highest malignancy degree expressed the lowest level of Cx43 protein. Subsequently, Hs578T and MCF-7 cells, which have the ability to form efficient GJs, were used in order to observe whether regulation of GJ function could influence the cytotoxicity of chemical drugs such as adriamycin. RA was used as potentiator of GJ. Increased cytotoxicity of adriamycin was observed upon RA treatment in Hs578T and MCF-7 cells. The function of GJ was downregulated by three different methods: i) Low-density cultures, which lack functional contacts; ii) drugs, by incubating cells with the GJIC inhibitors oleamide or $18-\alpha-\mathrm{GA}$; and iii) molecular biology, which resulted in $\mathrm{Cx} 43$ knockdown by siRNA. These methods provided the same results: Reduction of adriamycin cytotoxicity via inhibition of GJ was observed in high-density cultures, in which functional GJs were effectively formed, but was not observed in low-density cultures. These results suggested that GJ function could be enhanced to increase the antitumor activity of therapeutic agents in mammary cancer cells, which could become a novel therapeutic target of breast tumors.

Cancer cells (including liver cancer, lung carcinoma and breast carcinoma) are generally linked to loss of connexin and/or GJIC (15,31-33). Numerous studies have revealed the significant role of GJs in tumors, since recovered expression of connexin that forms GJs or recovered function of GJs could reduce the cell malignant phenotype $(11,34,35)$. The expression of connexin and its derived homotypic GJ suppressed the invasion of tumor cells $(36,37)$.

In view of this, we attributed both the protective and toxic effects of GJIC on adriamycin cytotoxicity to the intercellular propagation of molecular/chemical signals through GJs in breast cancer cells. Prior reports have indicated that GJs regulated the cytotoxicity of antineoplastic drugs through various mechanisms $(21,38,39)$. For example, heteromeric GJs composed of Cx26 and Cx32 enhanced the cytotoxicity of cisplatin in HeLa cells, as assessed by proliferative capacity, cell survival and induction of specific apoptotic caspases (21). GJIC was enhanced by simvastatin through protein kinase $\mathrm{C}$-mediated $\mathrm{Cx} 43$ phosphorylation, which enhanced etoposide toxicity in Leydig tumor cells (38). The efficacy of antineoplastic drugs was increased through a combinatorial treatment with substituted quinolines, which are specific class of GJ enhancers (39). This effect was similarly observed in tumors subjected to X-rays irradiation treatment. Berberine potentiates the cell apoptosis induced by X-rays irradiation, probably through enhancement of GJ activity (40). Apoptosis is currently recognized as a major mode of antineoplastic-induced or radiation-induced cell death $(41,42)$. It is possible that one explanation for these discrepancies is the GJ-mediated transmission of the 'death signal' from apoptotic cells to neighboring viable cells. This strategy, which is followed in GJIC-based therapies, depends on the so-called 'bystander effect' (BE) $(43,44)$. The $\mathrm{BE}$, a mechanism where a cytotoxic signal is transferred from targeted cells to neighboring cells, has been considered as an important therapeutic method (45). Numerous experiments reported that the BE promotes suicide gene therapy $(46,47)$. Therefore, several inducers of GJIC such as retinoids have been used to provide great potential to amplify the efficacy of suicide gene therapy via the $\mathrm{BE}(48,49)$.

However, in normal cells, GJIC could exert a protective effect, which is a markedly opposite effect to that exerted in tumor cells $(20,50)$. Nakase et al (50) reported that astrocytic GJs reduce apoptotic neuronal damage in cerebral ischemia. Hong et al (20) reported that the modulatory effect of GJIC on the cisplatin cytotoxic or protective effect depends on the oncogenic status of the cells, since the toxicity effect observed in tumor cells is opposite to that observed in normal cells, and these different effects are mediated by the same connexin. This phenomenon suggests that the protective effect is mediated by the transmission of survival signals among normal cells, the production of which is stimulated by the damaging effects of cisplatin exposure.

Upregulation of connexins and GJIC has been suggested as an antineoplastic strategy $(19,51)$. Conklin et al (51) reported that genistein and quercetin increase Cx43 expression and suppress the growth of breast cancer cells. He et al (19) demonstrated that tramadol and flurbiprofen inhibit the cytotoxicity of cisplatin via their effects on GJs. This observation suggests that the restoration of connexins expression and GJIC may have beneficial effects in cancer therapies.

Connexins are reliable markers for breast cancer behavior (52). Multiples studies have revealed that, in breast cancer patients, the expression of connexin proteins is correlated with clinicopathological biomarkers, including estrogen receptor (ER), progesterone receptor (PR) and human epidermal growth factor receptor 2 (HER2), which are normally used to predict the response of mammary cancer patients to therapy $(33,53)$. The Hs578T cell line used in the current study is a type of triple-negative breast cancer (TNBC), while the MCF-7 cell line is non-TNBC (ER+ and PR+) $(54,55)$. ER and PR status have traditionally been used to select patients suitable for tamoxifen treatment (56). Conklin et al (52) reported that there was a significant positive correlation between $\mathrm{Cx} 43$ and PR expression, while both $\mathrm{C} \times 32$ and $\mathrm{C} \times 43$ exhibited a strong, positive correlation with ER status. Previous studies have shown that estrogen-mediated activation of ER- $\alpha$ suppresses GJIC and $\mathrm{Cx} 43$ expression, resulting in endometrial tumor progression (57). Zhao et al (58) observed that progestin reduces the transcription of $\mathrm{Cx}_{4} 43$ in myometrial cells through a mechanism independent of PR. Whether the expression level of $\mathrm{Cx} 43$ in Hs578T and MCF-7 cells is correlated with ER or PR remains to be determined. However, the present results demonstrated that the function of GJ and the expression of $\mathrm{Cx} 43$ in breast cancer were not associated with the levels of any of the above three biomarkers (ER, PR or HER2), and that the influence of GJ on the antitumor activity of adriamycin was neither associated with these biomarkers.

The outcome of our findings implies that regulation of GJ could be used as a new target in the therapy of breast cancer. We propose that the expression of $\mathrm{Cx} 43$ is associated with the 
malignancy degree of breast cancer cells. The cytotoxicity of adriamycin on breast cancer cells can be regulated by GJ modulators and Cx43 siRNA, which appears to be dependent on GJIC. Taken together, these observations indicated that specific modulators of $\mathrm{Cx} 43$ may have therapeutic implications in breast cancer.

\section{Acknowledgements}

The present study was supported by research grants from the National Natural Science Foundation of China (Beijing, China; grant no. 81001457), the National Natural Science Foundation of Anhui (grant no. 1508085QH151), the Natural Science Foundation of the Provincial Education Department of Anhui (no. KJ2015A147) and the Scientific Research Project of Bengbu Medical College of Anhui Province (Bengbu, China; grant nos. BYKY1605ZD and BYKY1608ZD).

\section{References}

1. Siegel R, Ward E, Brawley O and Jemal A: Cancer statistics, 2011: The impact of eliminating socioeconomic and racial disparities on premature cancer deaths. CA Cancer J Clin 61: 212-236, 2011.

2. Bernzweig J, Heiniger B, Prasain K, Lu J, Hua DH and Nguyen TA: Anti-breast cancer agents, quinolines, targeting gap junction. Med Chem 7: 448-453, 2011.

3. Zhang S, Chen Y, Guo W, Yuan L, Zhang D, Xu Y, Nemeth E, Ganz T and Liu S: Disordered hepcidin-ferroportin signaling promotes breast cancer growth. Cell Signal 26: 2539-2550, 2014.

4. Li WJ, Zhong SL, Wu YJ, Xu WD, Xu JJ, Tang JH and Zhao JH: Systematic expression analysis of genes related to multidrug-resistance in isogenic docetaxel- and adriamycin-resistant breast cancer cell lines. Mol Biol Rep 40: 6143-6150, 2013.

5. Cao B, Li M, Zha W, Zhao Q, Gu R, Liu L, Shi J, Zhou J, Zhou F, Wu X, et al: Metabolomic approach to evaluating adriamycin pharmacodynamics and resistance in breast cancer cells. Metabolomics 9: 960-973, 2013.

6. Wang J, Wu L, Kou L, Xu M, Sun J, Wang Y, Fu Q, Zhang P and He Z: Novel nanostructured enoxaparin sodium-PLGA hybrid carriers overcome tumor multidrug resistance of doxorubicin hydrochloride. Int J Pharm 513: 218-226, 2016.

7. Gao M, Xu Y and Qiu L: Sensitization of multidrug-resistant malignant cells by liposomes co-encapsulating doxorubicin and chloroquine through autophagic inhibition. J Liposome Res: June 7, 2016 (Epub ahead of print).

8. Wei CJ, $\mathrm{Xu} \mathrm{X}$ and Lo CW: Connexins and cell signaling in development and disease. Annu Rev Cell Dev Biol 20: 811-838, 2004.

9. Trosko JE and Chang CC: Mechanism of up-regulated gap junctional intercellular communication during chemoprevention and chemotherapy of cancer. Mutat Res 480-481: 219-229, 2001.

10. Trosko JE and Ruch RJ: Gap junctions as targets for cancer chemoprevention and chemotherapy. Curr Drug Targets 3: 465-482, 2002

11. Yu M, Zhang C, Li L, Dong S, Zhang N and Tong X: Cx43 reverses the resistance of A549 lung adenocarcinoma cells to cisplatin by inhibiting EMT. Oncol Rep 31: 2751-2758, 2014.

12. Li Z, Zhou Z, Welch DR and Donahue HJ: Expressing connexin 43 in breast cancer cells reduces their metastasis to lungs. Clin Exp Metastasis 25: 893-901, 2008.

13. Saez JC, Berthoud VM, Branes MC, Martinez AD and Beyer EC: Plasma membrane channels formed by connexins: Their regulation and functions. Physiol Rev 83: 1359-1400, 2003.

14. McLachlan E, Shao Q and Laird DW: Connexins and gap junctions in mammary gland development and breast cancer progression. J Membr Biol 218: 107-121, 2007.

15. Choudhary M, Naczki C, Chen W, Barlow KD, Case LD and Metheny-Barlow LJ: Tumor-induced loss of mural Connexin 43 gap junction activity promotes endothelial proliferation. BMC Cancer 15: 427, 2015.

16. Aasen T: Connexins: Junctional and non-junctional modulators of proliferation. Cell Tissue Res 360: 685-699, 2015.
17. Czyż J, Szpak K and Madeja Z: The role of connexins in prostate cancer promotion and progression. Nat Rev Urol 9: 274-282, 2012.

18. Qin H, Shao Q, Curtis H, Galipeau J, Belliveau DJ, Wang T, Alaoui-Jamali MA and Laird DW: Retroviral delivery of connexin genes to human breast tumor cells inhibits in vivo tumor growth by a mechanism that is independent of significant gap junctional intercellular communication. J Biol Chem 277: 29132-29138, 2002.

19. He B, Tong X, Wang L, Wang Q, Ye H, Liu B, Hong X, Tao L and Harris AL: Tramadol and flurbiprofen depress the cytotoxicity of cisplatin via their effects on gap junctions. Clin Cancer Res 15: 5803-5810, 2009.

20. Hong X, Wang Q, Yang Y, Zheng S, Tong X, Zhang S, Tao L and Harris AL: Gap junctions propagate opposite effects in normal and tumor testicular cells in response to cisplatin. Cancer Lett 317: 165-171, 2012.

21. Tong X, Dong S, Yu M, Wang Q and Tao L: Role of heteromeric gap junctions in the cytotoxicity of cisplatin. Toxicology 310: 53-60, 2013.

22. Huang F, Li S, Gan X, Wang R and Chen Z: Propofol inhibits gap junctions by attenuating sevoflurane-induced cytotoxicity against rat liver cells in vitro. Eur J Anaesthesiol 31: 219-224, 2014.

23. Tong XH, Dong SY, Jiang GJ and Fan GF: Influence of Cx26/Cx32 gap junction channel on antineoplastic effect of etoposide in Hela cells. Nan Fang Yi Ke Da Xue Xue Bao 32: 329-332, 2012 (In Chinese).

24. Babaoglu M, Zumrutbas AE, Acar IC, Hatip FB, Kucukatay V, Eskicorapci $S$ and Aybek Z: Gap junction expression and the effects of gap junction inhibitors in overactive bladder models: Does ovariectomy have a role? Int Urol Nephrol 45: 1001-1008, 2013.

25. Talhouk R, Tarraf C, Kobrossy L, Shaito A, Bazzi S, Bazzoun D and El-Sabban M: Modulation of Cx43 and gap junctional intercellular communication by androstenedione in rat polycystic ovary and granulosa cells in vitro. J Reprod Infertil 13: 21-32, 2012.

26. Wu J, Taylor RN and Sidell N: Retinoic acid regulates gap junction intercellular communication in human endometrial stromal cells through modulation of the phosphorylation status of connexin 43. J Cell Physiol228: 903-910, 2013.

27. Bier A, Oviedo-Landaverde I, Zhao J, Mamane Y, Kandouz M and Batist G: Connexin43 pseudogene in breast cancer cells offers a novel therapeutic target. Mol Cancer Ther 8: 786-793, 2009.

28. Shao Q, Wang H, McLachlan E, Veitch GI and Laird DW: Down-regulation of $\mathrm{Cx} 43$ by retroviral delivery of small interfering RNA promotes an aggressive breast cancer cell phenotype. Cancer Res 65: 2705-2711, 2005.

29. Ablasser A, Schmid-Burgk JL, Hemmerling I, Horvath GL, Schmidt T, Latz E and Hornung V: Cell intrinsic immunity spreads to bystander cells via the intercellular transfer of cGAMP. Nature 503: 530-534, 2013.

30. Vliagoftis H, Ebeling C, Ilarraza R, Mahmudi-Azer S, Abel M, Adamko D, Befus AD and Moqbel R: Connexin 43 expression on peripheral blood eosinophils: Role of gap junctions in transendothelial migration. Biomed Res Int 2014: 803257, 2014.

31. Hsiao PJ, Jao JC, Tsai JL, Chang WT, Jeng KS and Kuo KK: Inorganic arsenic trioxide induces gap junction loss in association with the downregulation of connexin 43 and E-cadherin in rat hepatic "stem-like" cells. Kaohsiung J Med Sci 30: 57-67, 2014.

32. Zhang D, Chen C, Li Y, Fu X, Xie Y, Li Y and Huang Y: Cx31.1 acts as a tumour suppressor in non-small cell lung cancer (NSCLC) cell lines through inhibition of cell proliferation and metastasis. J Cell Mol Med 16: 1047-1059, 2012.

33. Teleki I, Krenacs T, Szasz MA, Kulka J, Wichmann B, Leo C, Papassotiropoulos B, Riemenschnitter C, Moch H and Varga $Z$ : The potential prognostic value of connexin 26 and 46 expression in neoadjuvant-treated breast cancer. BMC Cancer 13: 50, 2013.

34. Wu JF, Ji J, Dong SY, Li BB, Yu ML, Wu DD, Tao L and Tong XH: Gefitinib enhances oxaliplatin-induced apoptosis mediated by Src and PKC-modulated gap junction function. Oncol Rep: Oct 11, 2016 (Epub ahead of print).

35. Yu BB, Dong SY, Yu ML, Jiang GJ, Ji J and Tong XH: Total flavonoids of litsea coreana enhance the cytotoxicity of oxaliplatin by increasing gap junction intercellular communication. Biol Pharm Bull 37: 1315-1322, 2014. 
36. Hong X, Sin WC, Harris AL and Naus CC: Gap junctions modulate glioma invasion by direct transfer of microRNA. Oncotarget 6: 15566-15577, 2015.

37. Zhou JZ, Riquelme MA, Gu S, Kar R, Gao X, Sun L and Jiang JX: Osteocytic connexin hemichannels suppress breast cancer growth and bone metastasis. Oncogene 35: 5597-5607, 2016.

38. Chiu HW, Yeh YL, Wang YC, Huang WJ, Chen YA, Chiou YS, Ho SY, Lin P and Wang YJ: Suberoylanilide hydroxamic acid, an inhibitor of histone deacetylase, enhances radiosensitivity and suppresses lung metastasis in breast cancer in vitro and in vivo. PLoS One 8: e76340, 2013.

39. Shishido SN and Nguyen TA: Gap junction enhancer increases efficacy of cisplatin to attenuate mammary tumor growth. PLoS One 7: e44963, 2012.

40. Ferraroni M, Bazzicalupi C, Bilia AR and Gratteri P: X-Ray diffraction analyses of the natural isoquinoline alkaloids Berberine and Sanguinarine complexed with double helix DNA d (CGTACG). Chem Commun (Camb) 47: 4917-4919, 2011.

41. Sun H, Yang S, Li J, Zhang Y, Gao D and Zhao S: Caspase-independent cell death mediated by apoptosis-inducing factor (AIF) nuclear translocation is involved in ionizing radiation induced HepG2 cell death. Biochem Biophys Res Commun 472: 137-143, 2016.

42. Jo GH, Bögler O, Chwae YJ, Yoo H, Lee SH, Park JB, Kim YJ, Kim JH and Gwak HS: Radiation-induced autophagy contributes to cell death and induces apoptosis partly in malignant glioma cells. Cancer Res Treat 47: 221-241, 2015.

43. Kong H, Liu X, Yang L, Qi K, Zhang H, Zhang J, Huang Z and Wang H: All-trans retinoic acid enhances bystander effect of suicide gene therapy in the treatment of breast cancer. Oncol Rep 35: 1868-1874, 2016.

44. Yakovlev VA: Role of nitric oxide in the radiation-induced bystander effect. Redox Biol 6: 396-400, 2015.

45. Prise KM and O'Sullivan JM: Radiation-induced bystander signalling in cancer therapy. Nat Rev Cancer 9: 351-360, 2009.

46. Li S, Gu C, Gao Y, Amano S, Koizumi S, Tokuyama T and Namba H: Bystander effect in glioma suicide gene therapy using bone marrow stromal cells. Stem Cell Res 9: 270-276, 2012.

47. Leten C, Trekker J, Struys T, Roobrouck VD, Dresselaers T, Velde GV, Lambrichts I, Verfaillie CM and Himmelreich U: Monitoring the Bystander Killing Effect of Human Multipotent Stem Cells for Treatment of Malignant Brain Tumors. Stem Cells Int 2016: 4095072, 2016.
48. Li S, Gao Y, Pu K, Ma L, Song X and Liu Y: All-trans retinoic acid enhances bystander effect of suicide-gene therapy against medulloblastomas. Neurosci Lett 503: 115-119, 2011.

49. Yang J, Liu TJ, Jiang YX and Lu Y: ATRA enhances the bystander effect of suicide gene therapy driven by the specific promoter LEP 503 in human lens epithelial cells. Mol Vis 18: 2053-2066, 2012.

50. Nakase T, Fushiki S and Naus CC: Astrocytic gap junctions composed of connexin 43 reduce apoptotic neuronal damage in cerebral ischemia. Stroke 34: 1987-1993, 2003.

51. Conklin CM, Bechberger JF, MacFabe D, Guthrie N, Kurowska EM and Naus CC: Genistein and quercetin increase connexin43 and suppress growth of breast cancer cells. Carcinogenesis 28: 93-100, 2007 .

52. Conklin C, Huntsman D, Yorida E, Makretsov N, Turbin D, Bechberger JF, Sin WC and Naus CC: Tissue microarray analysis of connexin expression and its prognostic significance in human breast cancer. Cancer Lett 255: 284-294, 2007.

53. Sulkowska U, Wincewicz A, Kanczuga-Koda L, Koda M and Sulkowski S: Eventual proapoptotic or anti-apoptotic impact of aberrantly expressed Cx43 and Cx26 can depend on ER-alpha overexpression in human endometrioid adenocarcinoma. Gynecol Endocrinol 31: 604-608, 2015.

54. Tarasewicz E, Rivas L, Hamdan R, Dokic D, Parimi V, Bernabe BP, Thomas A, Shea LD and Jeruss JS: Inhibition of CDK-mediated phosphorylation of Smad3 results in decreased oncogenesis in triple negative breast cancer cells. Cell Cycle 13: 3191-3201, 2014.

55. Collins DC, Cocchiglia S, Tibbitts P, Solon G, Bane FT, McBryan J, Treumann A, Eustace A, Hennessy B, Hill AD and Young LS: Growth factor receptor/steroid receptor cross talk in trastuzumab-treated breast cancer. Oncogene 34: 525-530, 2015.

56. Ciocca DR and Elledge R: Molecular markers for predicting response to tamoxifen in breast cancer patients. Endocrine 13: $1-10,2000$.

57. Saito T, Tanaka R, Wataba K, Kudo R and Yamasaki H: Overexpression of estrogen receptor-alpha gene suppresses gap junctional intercellular communication in endometrial carcinoma cells. Oncogene 23: 1109-1116, 2004.

58. Zhao K, Kuperman L, Geimonen E and Andersen J: Progestin represses human connexin43 gene expression similarly in primary cultures of myometrial and uterine leiomyoma cells. Biol Reprod 54: 607-615, 1996. 